\title{
Corrigendum: The Complexities in Genotyping of Congenital Adrenal Hyperplasia: 21-Hydroxylase Deficiency
}

\author{
Duarte Pignatelli ${ }^{1,2,3 *}$, Berta L. Carvalho ${ }^{4,5}$, Aida Palmeiro ${ }^{6}$, Alberto Barros ${ }^{4,5}$, \\ Susana G. Guerreiro ${ }^{2,3}$ and Djuro Macut ${ }^{7}$ \\ ${ }^{1}$ Hospital S. João, Porto, Portugal, ${ }^{2}$ Department of Biomedicine, Faculty of Medicine of Porto, Porto, Portugal, \\ ${ }^{3}$ IPATIMUP/IBS Research Institute, University of Porto, Porto, Portugal, ${ }^{4}$ Genetics, Department of Pathology, Faculty of \\ Medicine, University of Porto, Porto, Portugal, ${ }^{5}$ I3S Research Institute, University of Porto, Porto, Portugal, ${ }^{6}$ Clinical Genetics \\ Center, Porto, Portugal, ${ }^{7}$ Clinic of Endocrinology, Diabetes and Metabolic Diseases, Faculty of Medicine, University of \\ Belgrade, Belgrade, Serbia
}

OPEN ACCESS

Approved by: Frontiers Editorial Office, Frontiers Media SA, Switzerland

${ }^{*}$ Correspondence: Duarte Pignatelli dpignatelli@yahoo.com

Specialty section This article was submitted to Systems Endocrinology,

a section of the journal Frontiers in Endocrinology

Received: 18 February 2020 Accepted: 20 February 2020 Published: 04 March 2020

Citation: Pignatelli D, Carvalho BL, Palmeiro A Barros A, Guerreiro SG and Macut D (2020) Corrigendum: The Complexities

in Genotyping of Congenital Adrenal Hyperplasia: 21-Hydroxylase Deficiency. Front. Endocrinol. 11:113. doi: 10.3389/fendo.2020.00113
Keywords: $210 \mathrm{H}$ deficiency, $\mathrm{CAH}-$ congenital adrenal hyperplasia, adrenal cortex, androgen excess syndromes, genotyping, endocrine genetics, rare diseases, disorders of sex development

\section{A Corrigendum on}

The Complexities in Genotyping of Congenital Adrenal Hyperplasia: 21-Hydroxylase Deficiency by Pignatelli, D., Carvalho, B. L., Palmeiro, A., Barros, A., Guerreiro, S. G., and Macut, D. (2019). Front. Endocrinol. 10:432. doi: 10.3389/fendo.2019.00432

In the article, an author's name was incorrectly spelled as Djuro Maçut. The correct spelling is Djuro Macut. In addition there was an error in affiliation 7. Instead of "Department of Endocrinology, Diabetes and Metabolic Diseases, Faculty of Medicine, University of Belgrade, Belgrade, Serbia," it should be "Clinic of Endocrinology, Diabetes and Metabolic Diseases, Faculty of Medicine, University of Belgrade, Belgrade, Serbia."

The authors apologize for this error and state that this does not change the scientific conclusions of the article in any way. The original article has been updated.

Copyright $\odot 2020$ Pignatelli, Carvalho, Palmeiro, Barros, Guerreiro and Macut. This is an open-access article distributed under the terms of the Creative Commons Attribution License (CC BY). The use, distribution or reproduction in other forums is permitted, provided the original author(s) and the copyright owner(s) are credited and that the original publication in this journal is cited, in accordance with accepted academic practice. No use, distribution or reproduction is permitted which does not comply with these terms. 